\title{
Las culturas urbanas, se apropian de la hora del recreo
}

\section{Urban cultures, appropriate the time of recreation}

\author{
Diego Vicente Illescas Reinoso ${ }^{1}$ \\ ${ }^{1}$ Universidad Católica de Cuenca \\ *dillescasr@ucacue.edu.ec
}

DOI: https://doi.org/10.26871/killkana_social.v2i3.325

\begin{abstract}
Resumen
"Las Culturas Urbanas, se apropian de la hora del recreo", es el resultado de una investigación en la cual se realizó un estudio etnográfico dentro de una institución educativa secundaria particular mixta de Cuenca, en la que se analiza la dinámica que tienen los colectivos para agruparse y formar las culturas juveniles. Se estudia cómo construyen sus identidades, cuáles son los entornos en los cuales los jóvenes del colegio interactúan, y cómo utilizan el espacio público dentro de la ciudad. En este estudio cualitativo se aplica la técnica de la etnografía, cuyo objetivo fundamental es analizar la construcción de las identidades y las culturas juveniles, y su entorno, y como este es capitalizado por los grupos de adolescentes para conocer sus necesidades, intereses e interacciones. Se analiza cómo estos jóvenes conciben el "espacio público", de qué manera interactúan en él; dónde y para qué se reúnen, qué hacen, cómo se vinculan entre ellos, si son rechazados o aceptados en este. La investigación permitió descubrir, identificar y describir diversas culturas juveniles inmersas en la institución educativa, y cómo van construyendo sus identidades en los diversos entornos y cómo convierten en su territorio el espacio público de la ciudad. Además, se estudia a las culturas urbanas como se enfocan conceptualmente desde la comunicación y cultura y se afianzan en los estudios culturales latinoamericanos.
\end{abstract}

Palabras clave: Culturas Urbanas, identidad, espacio público, etnografía.

\begin{abstract}
"Urban Cultures, appropriate the time of recreatio", is the result of an investigation in which an ethnographic study was conducted within a mixed private secondary educational institution of Cuenca, which analyzes the dynamics of the collectives to group and form youth cultures. It is studied how they construct their identities, which are the environments in which the young people of the school interact, and how they use the public space within the city. In this qualitative study, the technique of ethnography is applied, whose fundamental objective is to analyze the construction of youth identities and cultures, and their environment, and how it is capitalized by groups of adolescents to know their needs, interests and interactions. It is analyzed how these young people conceive the "public space", how they interact in it; where and for what they meet, what they do, how they are linked to each other, if they are rejected or accepted in it. The research made it possible to discover, identify and describe various youth cultures immersed in the educational institution, and how they are constructing their identities in the different environments and how they convert the public space of the city into their territory. In addition, urban cultures are studied as they are conceptually focused on communication and culture and are consolidated in Latin American cultural studies.
\end{abstract}

Key words: Urban Cultures, identity, public space, ethnography.

\section{Introducción}

Las Culturas Juveniles adquieren cada vez más relevancia como objeto de investigación y debate en las agendas de las Ciencias Sociales. En Ecuador y sobre todo en la ciudad Cuenca, no ha sido frecuente el empleo de esta categoría en los estudios culturales ni en los estudios sobre juventud. Es necesario fortalecer una línea de trabajo sobre culturas juveniles y articular vínculos teóricos y académicos con otros centros interesados en el tema. En Cuenca, existen pocos estudios acerca de la juventud; la mayoría de las aproximaciones al tema han sido superficiales o se han enfocado en ámbitos de estudio del aspecto legal, psicológico, médico o migratorio, más que en el de la identidad. Mauro Cerbino inicia el estudio de los jóvenes guayaquileños y a partir de este momento y de los resultados obtenidos, surge la necesidad de dar un vuelco a las investigaciones con relación a la juventud ecuatoriana y en particular la cuencana.

Para comprender una época, una etapa, un momento, hay que conocer a fondo sus protagonistas, y en las sociedades contemporáneas, son precisamente los jóvenes los personajes principales quienes actualmente han puesto a "temblar" y han rechazado los preceptos iluminados de la modernidad que han regido durante siglos, planteando unas 
nuevas formas de vida, sensibilidades y nuevas culturas; los jóvenes de hoy forjan a un nuevo mundo en la cotidianidad de sus vidas, en su vestir y actuar, en sus consumos culturales en general, es en sus conductas, sus creencias y hábitos que generan un cambio, que superficialmente no denota; pero que está determinado el inicio de otra etapa en la historia de la cultura juvenil.

Estamos en una etapa donde los jóvenes han construido espacios de sociabilidad nuevos, y están constantemente creando nuevos significantes como el vestuario, peinado, uso del espacio público, entre otros, que poseen sentidos diferentes, y que a su vez, contribuyen para crear otras identidades; precisamente estas identidades hablan del mundo y la forma de vivirlo en el transcurso diario, hablan del presente y cómo los jóvenes se apropian de este momento tan especial de la historia y cómo en su vida cotidiana van construyendo el futuro. Las identidades juveniles, hoy reflejan la vida misma; una vida formada de un collage de elementos de otras épocas, una mezcla de gustos que en otros tiempos podrían haber parecido absurdos, por ejemplo jóvenes que en una semana asisten al colegio, al teatro, a manifestaciones, a un encuentro deportivo, a un concierto de rock pesado y el sábado lucen su mejor traje de gala en una fiesta de quince años; estas identidades de "camaleón", hoy encuentran cabida en nuestras sociedades fragmentadas, llenas de corrientes, de estilos, y prácticas, que conviven armónicamente o por lo menos en un aparente equilibrio dentro de un mismo sistema, creando nuevos modos de ver y leer al mundo.

\section{Marco Teórico o Antecedentes}

Los jóvenes existen en lo cotidiano, los vemos por todos lados, en las calles, en el colegio, en las fiestas, en el barrio, en los parques, en los centros comerciales, entre otros lugares. No negamos esa realidad que conforman, ni tampoco esa etapa del individuo humano intermedia entre la niñez y la edad adulta. Lo que se pone en duda es la existencia de un objeto teórico "juventud" que problematice la realidad "jóvenes", e integre con ello un marco de análisis para su comprensión.

Roberto Brito Lemus, en su ensayo "Hacia una sociología de la juventud", sostiene que no existe una construcción teórica que conceptúe de manera adecuada a la juventud, ni un objeto teórico, construido desde la misma ciencia social, denominado con ese término.

"Esta es una duda epistemológica que hace referencia, no a la negación de la realidad, sino a la existencia de su correspondiente teórico. La investigación social sobre juventud no ha establecido una ruptura epistemológica con la realidad, para construir un objeto teórico que sirva como referente conceptual y al mismo tiempo, como el fundamento de una disciplina científica para el estudio y comprensión de la juventud". (Brito Lemus, 1998)

Néstor García Canclini en su libro "Diferentes, Desiguales y Desconectados" Mapas de la interculturalidad, sostiene que un avance notorio en el conocimiento de la juventud ha sido indagar que significa ser joven no como una pregunta generacional, menos aún pedagógica o disciplinaria. "Quiero examinar en qué sentido es una pregunta social, o sea una averiguación sobre el sentido intercultural del tiempo" (García Canclini, 2004)

Se analiza cómo se construyen las culturas juveniles, a partir de identidades y entornos sociales como el colegio, sus jorgas, grupos, entre otros. Además, cómo estas culturas juveniles establecen su territorio dentro del espacio público cuencano. Es importante, por ello, conocer la aproximación teórica que existe sobre "culturas juveniles", de acuerdo con nuestro centro de interés temático y los objetivos planteados.

En Ecuador, Mauro Cerbino empieza el estudio de los jóvenes guayaquileños, y a partir de este momento y de los resultados obtenidos, surge la necesidad de dar un vuelco a las investigaciones con relación a la juventud ecuatoriana y en particular cuencana. (Cerbino, 1999) plantea que la investigación sobre culturas juveniles en Guayaquil partió de un enfoque conceptual, formulando la hipótesis fuerte: "Si no se investiga la dimensión cultural en la cual se desenvuelven los jóvenes cotidianamente, la comprensión que se puede tener de ellos será siempre sesgada, parcializada y prejuicial." (Cerbino, 1999)

Reguillo (2000), sitúa a los jóvenes, pese a las diferencias de clase, de género, de edad, de etnias y que comparten varias características que pueden considerarse definitorias de las culturas juveniles: (Reguillo, 2000)

Las culturas juveniles poseen una conciencia planetaria, globalizada, que puede considerarse como una vocación internacionalista. Nada de lo que pasa en el mundo les es ajeno. Se mantienen conectados a través de complejas redes de interacción y consumo. Priorizan los pequeños espacios de la vida cotidiana como trincheras para impulsar la transformación global. El barrio o el territorio han dejado de ser el epicentro del mundo. (Reguillo, 2003)

Para los jóvenes, además de constituir un espacio de instrucción, el colegio es donde se establecen vínculos que perduran en el tiempo. Es un lugar de encuentro con amigos y conocidos que comparten la rutina escolar, y aquellos espacios en que la institución los sitúa y en los que interactúan.

También se indagó cómo las culturas juveniles formadas desde el colegio, se apropian del espacio público de nuestra ciudad; por lo tanto, abordamos esta categoría conceptual, "espacio público", desde la óptica de algunos autores y la perspectiva de nuestro interés que son los jóvenes.

Espacio Público. - En Cuenca, los temas relacionados con el espacio público han sido tan recurrentes en periódicos, noticieros y conversaciones cotidianas, en donde señalan los aciertos y desaciertos de las políticas públicas. Lo indiscutible es que aquí la mayoría del espacio público está privatizado. Estamos convencidos de que el espacio público, lejos de convertirse en el sitio de las controversias, puede llegar a ser el de las coincidencias, sin dejar a un 
lado lo importante de las diferencias en el marco de la democracia y de la ciudad.

Uno de los autores que tratan el tema del espacio público es Jürgen Habermas, en su libro "Historia y Crítica de la opinión pública":

"Que el espacio público se da cuando individuos con uso de razón se reúnen en una esfera pública controlada por la autoridad y pueden expresarse contra el Estado. Al hacer pública su expresión a través de los medios de comunicación y la publicidad se genera opinión pública". (Habermas, 1981)

Para Habermas (1981), el espacio público es una especie de foro crítico, una suerte de tribunal de la razón, delante del cual el poder político debe legitimar sus decisiones. Este espacio público ha sido restringido por el estado moderno debido a la "socialización del Estado", que ha conducido a una "estatización de la sociedad". El Estado ha intervenido en el intercambio y en el trabajo que antes se reservaban a la esfera privada. De esa manera, esta esfera pierde sus funciones económicas, y se limita a las relaciones familiares que también han perdido su intimidad debido a la penetración de los medios de comunicación en su seno.

Ángela Garcés Montoya, sostiene que, en la diferenciación y separación entre el mundo adulto y el mundo joven, el espacio público urbano es importante en la socialización de los jóvenes al margen de los adultos: "El espacio público le permite al joven alejarse de los espacios familiares, escolares y laborales, para construir otro espacio no institucionalizado, no regulado, ni determinado por reglas preestablecidas. Así la calle, la esquina, el parque cobran nuevos significados; ese lugar de encuentro de los jóvenes, se trata de un lugar creado por ellos y regido por sus propias normas, espacio donde la mirada del adulto no llega, y, por tanto, tampoco alcanza su poder de control". (Garcéz, 2004)

Las culturas juveniles urbanas se hacen visibles en los espacios públicos, y es ahí donde se reconocen sus propuestas de gestión y de acción. La visibilización juvenil existente en el espacio público, confirman la posibilidad que tienen los jóvenes de establecer los territorios juveniles, y ahí hay que darse la tarea de intentar reconocer cuáles son las características y las especificidades del sujeto juvenil urbano que actúa en el espacio público, que es uno de los puntos centrales de esta investigación.

En el contexto de esta normativa estricta e impuesta, los chicos deben desarrollar distintas estrategias para sobrevivir en el interior del colegio. Ellos perciben y expresan claramente la importancia de generar redes y grupos de confianza, en tanto son mecanismos de sobrevivencia en un medio que inicialmente se les presenta como hostil.

Culturas Juveniles. - En la década de los noventa, tanto en España como en México empieza a surgir el término de culturas juveniles. La escuela está representada por varios estudiosos del tema. Por el lado de España, se encuentra Charles Feixa (1999), con su libro El reloj de arena: culturas juveniles. Por parte de México, Rossana
Reguillo (2000), con Emergencia de las culturas juveniles: estrategias del desencanto.

"Las culturas juveniles son como un espacio donde las experiencias sociales de los jóvenes son expresadas colectivamente mediante la construcción de estilos de vida, distintivos, localizados fundamentalmente en el tiempo libre o en espacios intersticiales de la vida institucional, también definen la aparición de microsociedades juveniles, con grados significativos de autonomía respecto de las instituciones adultas". (Feixa, 1999)

Tania Arce (2008), se pregunta ¿qué tan útil es categorizar a los grupos que surgen como expresiones alternas a la sociedad? Por un lado, sostiene que el uso de conceptos sirve para delimitar y hacer hincapié en la independencia y su diferencia de sus expresiones con la sociedad "adulta", "dominante", o alguna otra variación. Sus propuestas se vislumbran claramente en sus territorios, su jerga, su vestimenta y en sus preferencias sexuales y musicales, principalmente. Por otro, señala, sólo han servido para categorizar y estandarizar a los diversos grupos, con lo cual se creó una especie de miopía que no permite ver sus particularidades y sus propuestas como independientes e innovadoras, es decir, no permiten ver su expresión local ni particular entre cada uno de ellos. Sólo se logra generalizarlos como personas que tienen que contar con las mismas reacciones, propuestas o, en su defecto, comportamiento; y, por último, sólo se generan más confusiones al darles forzosamente un concepto global, es decir, crear categorías universalmente aplicables. (Arce, 2008)

\section{Metodología}

El campo de investigación donde se realizó trabajo fue un colegio de la ciudad de Cuenca-Ecuador, a los jóvenes "institucionalizados", que día a día comparten un sinnúmero de situaciones que los asemejan y diferencian. Se identificaron a jóvenes por sus características están inmersos en estas culturas juveniles, cómo se agrupan dentro de la institución, y cómo a partir de este sitio van al espacio público a generar una mayor interacción con sus pares.

Para esto es importante mencionar algunos criterios sobre el método de investigación cualitativa, "la etnografía”, que aplicamos en esta investigación. Stanton menciona que: "La etnografía requiere la inmersión completa del investigador en la cultura y la vida cotidiana de las personas asunto de su estudio, sin olvidar delimitar en la medida de lo posible el distanciamiento conveniente que le permita observar y analizar lo más objetivamente posible". (Stanton, 1996)

Además, el investigador no es menos "ser social" que aquellos que investiga, por el hecho de aparecer individualizado en la etnografía e individualmente en el campo. (Guber, 2004)

"Todas estas acciones juveniles están caracterizadas por un mismo tipo de cuestión, esto es, que constituyen un espacio que se construye, se opera y que debe ser entendido como espacio ritual. Por esa misma característica 
es que los jóvenes se sienten convocados por este espacio, ya que pueden construir en él una identidad como sujeto colectivo. Y esto, no sólo porque allí puedan socializarse en determinadas normas, prácticas y valores, sino que, en esos lugares, ellos pueden ser y encontrarse efectivamente como jóvenes". (Contreras, 2005)

Una de las principales técnicas que utilizamos y que nos brinda la etnografía es la "observación participante". Esta nos permitió interactuar con los jóvenes dentro del colegio, en sus momentos de estudio en el aula, en el recreo, en las actividades curriculares y extracurriculares que cumplían, en fin, en todo contacto que se tuvo con ellos. Por esto es importante destacar lo que menciona Rosana Guber en su texto "Etnografía" sobre esta técnica:

"La observación participante consiste en dos actividades principales: observar sistemática y controladamente todo lo que acontece en torno del investigador, y participar en una o varias actividades de la población. La participación pone el énfasis en la experiencia vivida por el investigador apuntando su objetivo a estar dentro de la sociedad estudiada". (Guber, 2001)

Con estos antecedentes se inició esta etapa de observación y contacto permanente con los jóvenes lo que permitió una relación directo con los chicos, entablar una amistad y realizar observación participante en forma directa. Retomo las palabras de Rosana Guber cuando menciona sobre el valor de la observación participante:

"La presencia directa es, indudablemente una valiosa ayuda para el reconocimiento social porque evita algunas mediaciones, ofreciendo a un observador crítico lo real en toda su complejidad. La observación participante es el medio ideal para realizar descubrimientos, para examinar críticamente los conceptos teóricos y para anclarlos en realidades concretas, poniendo en comunicación distintas reflexividades". (Guber, 2001)

\section{Resultados}

En esta investigación se aplicó el método etnográfico en una institución educativa de Cuenca, y mediante la inserción en los grupos juveniles por parte del investigador se pudo identificar a seis tipos de movimientos urbanos dentro del colegio de jóvenes "institucionalizados", que día a día comparten un sinnúmero de situaciones que los identifican y diferencian. Se identificaron a los chicos que están inmersos en estas culturas juveniles, cómo se agrupan dentro de la institución, y cómo a partir de este sitio van al espacio público a generar una mayor interacción con sus pares. Resumiremos a continuación el informe y resultados de la investigación con los grupos de los jóvenes de las culturas urbanas integradas en el colegio.

\subsection{El metal como género en el colegio}

El primer acercamiento fue con Cristian (Informante 1), un joven sencillo, excelente estudiante, de carácter dócil, y un poco tímido. Vestía correctamente su uniforme escolar, su peinado era impecable, sus libros y cuadernos correctos.
Sorprendió cuando dijo "Profe, yo le puedo ayudar en su trabajo". Imaginé que era amigo de chicos que pertenecían a una de estas jorgas, pero me asombré cuando me comentó que era él quien pertenecía a una tribu urbana. Desde ese momento nació una conexión directa entre los dos, que era necesario aprovechar en momentos claves, puesto que no había como descuidar los estudios, las clases ni a los otros jóvenes.

Cristian se identifica con el grupo de los metaleros, siempre ha sido parte de ellos. Desde pequeño siempre ha escuchado el rock. En casa, sus hermanos mayores escuchaban esa música y en su mente se familiarizó y creció con ella desde los diez años de edad. El escuchar rock le permitió incursionar en un grupo: Empecé a rebelar un poco cuando estaba en cuarto curso, tenía 15 años: me dejé crecer el pelo, me vestía de negro y en el colegio había compañeros que eran rockeros, ellos me enseñaban un poco qué grupos de música debía escuchar, cómo debí iniciar y qué debía saber. (I-1)

Dentro de esta cultura existen dos tipos de grupos: el uno son los metaleros, que abarcan géneros musicales como el heavy metal, el death metal, el trash; y el otro grupo son los Blackqueros o Satánicos, que tienen gusto por la música anticristiana, música satánica.

Cristian ingresó a este grupo por sus amigos del colegio. Se reunían a la hora del recreo, en el rincón más alejado del centro de la institución, a conversar sobre música. Era un grupo que tenía los mismos gustos por el rock, y estos amigos le invitaron a participar de las experiencias del grupo: Nos encontrábamos en la calle y comentábamos nuestros problemas de la casa o con la novia, nos reuníamos en la esquina de la Universidad Estatal a tomar licor, en donde paran los rockeros, todos vestidos de negro. Llegué la primera vez, me saludaron y me dieron confianza, $y$ desde ese momento me quedé en ese grupo. (I-1)

Los metaleros en Cuenca no tienen ningún ritual para ingresar al grupo. Piensan que no tiene por qué haberlo: "La gente toma sus propias decisiones, en nuestro grupo se necesita solamente la disposición a entrar, el respeto mutuo y el gusto por el rock". Cuando ingresas a los metaleros, los líderes dividen a la gente, unos son los que les acompañan a estos a todo lado y otros sólo están un instante, comparten un momento y nada más. En mi caso, yo me encuentro con ellos todos los jueves o cuando sé que hay algún concierto de música rock, ese momento comparto con mi grupo. (I-1)

\subsection{El punk como estilo}

En las observaciones que realizamos en el colegio llamó la atención un joven de dieciséis años de edad, que cursa el primer curso de bachillerato: Pablo (Informante 2 ), un chico callado en clases, respetuoso y atento, que en sus estudios no tenía inconvenientes porque cumplía con sus responsabilidades. Pablo se identifica con los punkeros, especialmente por la música que escuchan: La razón de ser de los punkeros es una combinación de tipo metal pero que no vamos a la exageración ni al desenfreno. (I-2) 
Incursionó en esta cultura juvenil cuando se cambió de vivienda, aproximadamente hace cuatro años, y esto también implicó cambiarse de colegio. En el nuevo barrio conoció amigos que se inclinaban por esta tendencia. Y estos amigos del barrio también estaban en el colegio donde ingresó Pablo.

No fue difícil acoplarse a este nuevo estilo de vida y sus nuevos amigos le brindaron toda la confianza. No tuvo que pasar por ningún ritual para ingresar a este grupo. Ahora, para que un nuevo miembro ingrese tiene que coincidir con sus ideas, y el primer día de ser admitido tiene que beber licor y emborracharse hasta perder el conocimiento. Además, en el barrio debe participar en las competencias deportivas que se organiza. Es un grupo en el cual se llevan bien, son solidarios entre ellos, lo que les permite consolidar el gusto y la estética de esta jorga. El gusto musical se ha convertido en el primer punto de identificación entre ellos, y esto a su vez les ha servido para unirse alrededor de su música.

A Pablo, desde pequeño, lo que más le llamó la atención de estos grupos es la forma de vestirse y el color negro, que le impacta: Me gusta pintarme las uñas de negro, delinearme los ojos, el estilo de peinado y sobre todo la música. Pero lo principal, lo que más me impactó, es el color negro. (I-2) Esto le ha permitido destacarse dentro del colegio, porque es el que más usa ropa y accesorios negros, y es el único de su jorga que se pinta el rostro. Antes de ingresar a este grupo Pablo se identificaba como metalero, pero cuando ingresó al colegio y se cambió de barrio se identificó como punkero.

La manera de convocarse entre ellos, se ha convertido en un estilo de vida propio. El celular está en primer plano. A pesar de que en este colegio está prohibido el uso del móvil, los chicos buscan la manera para llevarlo y cuando se reúnen en la hora de recreo a escondidas lo usan. Fuera del colegio la manera para convocarse es en el Internet, especialmente en el Facebook, se inscriben en esta red social y mediante esta manera se escriben: $E l$ Facebook es algo súper bueno para nosotros y chévere porque conocemos a más gente que tiene nuestro estilo, se comunican con nosotros, dejan y dejamos mensaje. El celular es importantísimo más con mensaje y chateo y una manera de convocarnos es con música, estamos cantando entre todos. (I-2)

El color con el cual se identifica este grupo principalmente es el negro, pero también lo mezclan con el blanco. Su manera de vestir es interesante. Usan zapatos que tengan los dos colores. Sus camisetas o buzos pegados al cuerpo y el pantalón siempre jean, éste no muy apretado. Todos utilizan piercing y todos tienen tatuajes en la espalda. Algo que identifica a los punkeros son las "flamas"

La ropa y los accesorios los adquieren en el parque de las artesanías, conocido como "parque de los hippies" en el centro de la ciudad. Y en los almacenes donde venden la ropa, de los cuales existen en Cuenca lugares específicos.

\subsection{El mundo divertido de los patinadores}

Danny (I-3) es un joven de dieciocho años de edad que se identifica con los skateboards que son los que practican el patinaje en tabla o patineta. Por lo general gustan de los estilos que realizan en la calle, los estilos urbanos, motivo por el cual lo llaman el "patinaje urbano", porque en Cuenca no existe un lugar, como en otras ciudades, donde se pueda patinar. Por ello, estos muchachos tienen que recorrer toda la ciudad buscando un espacio para practicar su afición.

El skateboarding o monopatinaje es considerado como deporte que se practica con un skateboard en cualquier parte de una calle donde se pueda rodar, aunque también se puede patinar sobre cualquier sitio, ya que es un deporte libre. Por ejemplo, piscinas, escaleras, calles. En él, el objetivo es buscar la belleza al manejarlo; no es un deporte que esté directamente vinculado a algún tipo de competición, por lo tanto, se podría denominar como libre.

A este grupo de jóvenes, dentro del colegio, se los identifica como los "SK 8", y comenzaron a relacionarse por amigos que practicaban este deporte. Un amigo de ellos vestía con un tipo de ropa especial, la marca era exclusiva, sólo para patinadores, lo cual sin duda generó un impacto en los chicos, que empezaron a gustar de la vestimenta y a interesarse por la práctica de esta afición. La idea la trajo Danny, cuyos hermanos mayores en EE.UU. y empezaron a mandar artículos, ropa y la patineta, videos de la práctica y competencias. Así nació el gusto por este género.

Para ingresar a este grupo no se rigen por algún requisito o algún ritual, simplemente tener las ganas decididas de practicar este deporte y "ser valientes": Muchos se han decepcionado con dos o tres caídas, dejan la patineta o tienen patinetas baratas, se partió la patineta y dejan rápidamente el grupo. Este deporte hay que tener condiciones económicas altas porque la tabla de patinaje es cara, al igual que los zapatos y la ropa. (I-3)

En cuanto a la música como elemento de identificación en este grupo, es básica y fundamental. El hip-hop y la música electrónica son los géneros con los que se identifican. Necesariamente tiene que gustarles esta música para estar dentro del grupo.

El graffiti, junto con el baile break en la etapa inicial y ulteriores bailes como el hop-rock o el electric-boogie al son de músicas como el rap o el raggamufin, constituye la actividad esencial y emblemática del movimiento urbano bautizado como hip-hop y que desde hace ya más de veinte años se desarrolla en los espacios públicos de las grandes ciudades occidentales. La práctica del skating, o patinaje en tablas, puede incluirse también como una actividad artístico-deportiva favorita de algunos miembros del mundo hip-hop, quienes, una vez alcanzada la necesaria destreza técnica, organizan reuniones para exhibirse a bordo de sus tablas por plazas, parques y calles, salvando, mediante plásticas piruetas, los desafiantes obstáculos del medio urbano.

Los colores distintivos de los skateboards son el café y el negro, son los colores más usados con el típico jean, 
porque "aguanta todas las caídas", y por lo general la ropa es floja. Utilizan piercing, y así marcan su personalidad. Algo característico es el peinado. Se peinan con los pelos parados, hecho punta. Los pantalones son bien bajos. Y las casacas son anchas, pero de buena marca. Los zapatos mandan mucho en este deporte porque tienen que aguantar en la tabla. No se utiliza cualquier zapato, porque estos no se adhieren a la patineta. Los zapatos tenían que ser de marca.

\subsection{La "people" de los batracios}

Es el caso de Sebastián, o Sebas (Informante 4) como le llamaban sus amigos, un chico de 18 años de edad que desde temprana edad aprendió lo que él llama "los vicios de la calle". Un muchacho con una serie de problemas conductuales dentro de la institución. Se le solía llamar la atención por su comportamiento inadecuado, tanto dentro del aula como en la hora de recreo.

Con Sebas es un mundo diferente. En su vida estaban ocultas una serie de manifestaciones que ni siquiera podía imaginar. Sus amigos estaban inmersos en drogas y delincuencia. Verdaderamente tuve miedo al ingresar en este grupo, sobre todo por las condiciones que me plantearon: "Si nos delata le bajamos". Una propuesta bastante amenazadora, pero había que tomar el riesgo, y con las debidas precauciones inicié las observaciones, a sabiendas de que Sebastián era mi informante clave, al cual iba a realizar la entrevista a profundidad.

Las observaciones las realizamos tanto en el colegio como en el lugar donde ellos tenían, por así decirlo, su centro de operación. La cita era por las noches. Se trataba de un grupo numeroso, integrado por chicos y chicas, entre quienes el licor estaba presente y el olor a marihuana era característico. Se identifican como "los vagos de la calle". La jorga se llama "The People" ("la gente", en español). Se había formado seis años atrás, como un grupo de amigos a los que les gustaba ir a la discoteca. Se juntaron por amistades y conocidos que vivían en un mismo barrio, y algunos eran compañeros en el colegio. "Somos panelas y fieles y nos cuidamos las espaldas".

No tienen ningún ritual de ingreso para los que quieran ingresar, pero son muy cuidadosos. Los mismos integrantes de esta jorga traen a sus conocidos o amigos, y si son confiables ingresan. No se consideran pandilleros: Hay diferentes grupos en que tú tienes la oportunidad de entrar; eso es decisión propia, a nadie le obligamos a entrar o no al grupo. A veces de muy joven tienen amigos que les influyen a entrar en una jorga o en otra. (I-4)

Al consultarle a Sebas qué significa en su vida estar en el grupo, manifiesta que es algo demasiado importante. En la calle se siente importante y anda tranquilo, se lleva con todos, eso le ha dado importancia y consiguió ser líder en la actualidad.

Sus primos mayores le influenciaron y le enseñaron "las cosas de la calle": Me sentí llamado la atención por la calle y ahora soy lo que soy. Mi madre conoce que yo salgo con vagos, a veces yo mismo le cuento que llego con celulares que he robado. Me aconseja que no siga así, otras veces me dice que cambie., pero no le hago caso. (I-4) La situación familiar del resto de integrantes del grupo es diversa. Muchos jóvenes salen de la casa a la hora que sea y a veces no llegan ni siquiera a dormir durante semanas. Toman demasiado alcohol y con frecuencia.

La situación en la hora del recreo era diferente. Se reunían pocos chichos, se llevan con todos. Sebas era un muchacho bastante bromista. De todas maneras, se asustaban de él: Yo pedía plata y de miedo me la daban. En el recreo me sentaba a lado de los juegos a comer algo. Nos dedicábamos a reírnos y a hablar de las cosas que hacíamos. Me preguntaban de mi gente y mis primos que eran famosos en la ciudad por sus fechorías. El celular es básico para la convocatoria a través de mensajes de texto. Otro medio que utilizan es el Facebook. Estar en este grupo ha cambiado su personalidad.

La vestimenta de los batracios o de la gente "vaga", como se consideran, es ancha, con los zapatos, pantalones, camisetas bien anchas. Muchos de los pantalones son "pescadores" o "capris", es decir el largo de la manga del pantalón pasa un poco de la rodilla. El corte de pelo tiene que ser lo más pequeño posible y plano a los dos lados, todos utilizan aretes o pendientes en sus orejas. El grafiti se ha convertido en su forma de expresión: sus libros, cuadernos, mochilas están llenas de estos, además de postes, paredes, bancas, pisos. Siempre va el nombre del grupo acompañado de una hoja de la planta de marihuana. Algo característico de este grupo son los tatuajes en cualquier parte del cuerpo. Se tatúan una $\mathrm{P}$ grande, que es la inicial del nombre del grupo, "People": Lo hacemos por el cariño y amor que se le tiene a la gente del grupo. (I-4)

Dentro de la ciudad de Cuenca este grupo se ubica por el sector de un centro comercial popular, el "Gran Aki", ubicado en el barrio Monay. La mayoría de chicos vive por este sector.

\subsection{Los traviesos son batracios}

Los "batracios", como se conoce a los reguetoneros, dentro del colegio tienen varias direccionalidades o ramificaciones. Aparte del grupo que acabamos de describir existe otro con una manera particular de integración. Existe un grupo de jóvenes dentro del colegio que integran una cultura juvenil que se ha extendido por toda la ciudad, con líderes ajenos al establecimiento, que tienen una situación organizacional definida y estricta. Nadie ajeno al grupo o adulto puede ingresar a éste; menos investigar u observar; sin embargo, a través de los alumnos pude recolectar información y acercarme a ellos lo más posible.

Esta agrupación se llama "Los Traviesos". Es un grupo reguetonero o batracio. Entre ellos se consideran delincuentes, pues cometen fechorías como robo a mano armada, asaltos. Estos jóvenes se distribuyen por toda la ciudad en diferentes lugares "tomados" por estos grupos. Existen Traviesos en la Plaza del Arte, en la ciudadela Álvarez, en 
el barrio del Banco de la Vivienda, pero principalmente esta tribu urbana está ubicada en el sector del "Vado", detrás de la Universidad de Cuenca, lugar muy inseguro dentro de la ciudad, puesto que precisamente está ocupada por los miembros de esta agrupación. Aquí se reúnen, se organizan, planifican sus actividades. En este lugar de la ciudad están los dos líderes de la agrupación: "El Papo y la Sandi”. Estos lugares están estrictamente marcados por ellos, "les pertenecen". Marcan su territorio en estas zonas como si fueran propias. Estos territorios no son visibles a cualquiera. $\mathrm{O}$, si se quiere, son visibles para unos e invisibles para otros. La visibilidad o invisibilidad no puede ser considerada al margen del sujeto que ve o no ve. No es una visibilidad estructural, sino "experiencial", pues está asociada a las representaciones de los encuentros. Los grupos urbanos cualifican los lugares, les atribuyen ciertas características, significados y sentidos. Según Jonathan, alumno de segundo de bachillerato, durante casi dos años intentó ingresar a este grupo junto a con su compañera de curso, Pamela. Habían pasado varias pruebas para ingresar, hasta que el momento llegó. La época en que Jonathan fue aceptado al grupo de los "traviesos", estuve precisamente en contacto con él y siguiéndole la pista. Tuve la oportunidad de comprobar los ritos de iniciación que debía cumplir. El primer día tenía que "plaquearse". El líder del grupo, con un cigarrillo encendido le quema en su mano izquierda, hasta que se produzca un edema grande y de allí queda marcado. Después tiene que pelear con el más "tuco de la jorga", digamos el más fuerte, grande y fornido, y así pasa la prueba. Estos chicos son raperos. Donde estén realizan sus rimas y bailes, usan extensiones que se colocan en diferentes partes del cuerpo, como en las axilas. Las chicas con sus piercings en la lengua, sus collares, aretes, manillas y extensiones en su ombligo, son algunas de las características identitarias del grupo.

\section{6 ¿Hay emos en el cole?}

Era la pregunta clásica que se hacían los docentes y autoridades del colegio, que generalizaban a los jóvenes con rasgos de identidad de alguna cultura juvenil. Para ellos todos eran emos, lo que significaba que no tenían la menor idea de la diversidad de jóvenes que existen en la institución; y mucho menos podían entender sus conflictos, sus ideas y pensamientos, o el verdadero sentir de los chicos.

Doris (Informante 5), una joven de 14 años de edad, empezó el año lectivo con dificultades en su rendimiento escolar. Su extravagante forma de llevar el uniforme y de maquillarse, a pesar de que estaba prohibido, preocupaba a los responsables del departamento de Orientación Vocacional, encargado de tratar los casos de rendimiento y conducta de los jóvenes. El psicólogo comentaba los rasgos extraños de la muchacha, y pedía por favor estar pendiente de ella, que la vigile. Empecé a interesarme por ella, una muchacha callada, que se ocultaba en un rincón, de perfil bajo. Tenía problemas con la mayoría de profesores, y hacia mí llegaba una lluvia de quejas casi todos los días. Tomé la decisión de hablar con su representante, y me pidió ayuda. Me contó la situación familiar en su hogar: un padre que la maltrataba, cuya rabia caía en Doris y la reacción de ella era salir de casa. Todas las tardes se pasaba en la calle. Su madre no sabía lo que hacía, no cumplía con las obligaciones escolares.

Doris es una chica muy sensible, abierta completamente al diálogo conmigo. Desde ese momento se estableció un lazo directo con ella y conocer en parte sus conflictos y dificultades, sus necesidades y su pensamiento. El primer impacto que tuve con ella fue ver sus brazos y muñecas siempre cubiertos con telas, o especies de manillas. Todo el curso conocía que tenía unas marcas que ocultaba con estas. Eso me dio el indicio de que estaba enrolada o integraba un grupo o jorga dentro del colegio.

En observaciones directas a las dos chicas, buscando e indagando su forma de vestir, su forma de comportarse, y sobre todo a través de conversaciones mantenidas con ellas, pude concluir que eran chicas "emo". El centro de interés de su jorga no estaba dentro sino fuera del establecimiento. Después de un tiempo me fue posible constatar que eran las únicas de este género dentro del colegio.

Los denominados "jóvenes emo" no se han propuesto ser un movimiento social, ni una tribu, ni una cultura. Ellos expresan sus gustos desde estéticas que reciclan y reinventan en las estéticas expandidas, en donde todas las estéticas son posibles, superando el agotamiento estético de la modernidad a través de un sincretismo que recrea, propone, renueva lo existente, toma algo viejo y lo rejuvenece generando novedad constante.

Los emo fundamentan su razón de ser en la denuncia de las actuales sociedades capitalistas en donde el confort, la tecnología, y el alto nivel de vida, no se compaginan con la soledad, el tedio, el hastío, el sin sentido y el aburrimiento que ellas mismas producen. Muchos de ellos son la manifestación del fracaso que las instituciones como familia, escuela, religión, han tenido, dejando de ser referente significativo para la mayoría de los jóvenes, y, en consecuencia, sin importancia como propuesta y respuesta. En ciudades contemporáneas donde la gente circula cada vez más y se encuentra cada vez menos, estos jóvenes arrojados a la soledad, hacen una ruptura con la tradición, la familia y la educación.

Doris afirma ser "emo" no por su estado de ánimo "sino porque es un estilo que se está imponiendo en Cuenca”, y por lo general los emo están en una etapa adolescente y son fáciles de distinguir en la calle. Cada tribu urbana, como hemos visto anteriormente, se caracteriza no sólo por una filosofía sino también por una forma de vestir muy particular, situación que también se presenta en el caso de los jóvenes emo. Aunque es importante aclarar que un joven que utilice la ropa descrita no significa que necesariamente pertenezca a esta cultura. 


\section{Conclusiones y Recomendaciones}

La juventud es un concepto cambiante que se reconstruye de manera permanente; se reproduce en lo cotidiano, y sus ámbitos de referencia son íntimos, cercanos y familiares: barrios, colegio, trabajo y otros. También se puede reproducir en lo imaginario, donde las comunidades y grupos de referencia marcan formas valorativas de lo juvenil; se construye en relaciones de poder definidas por las condiciones de alteridad, dominación, o desigualdad, unas veces superpuestas entre sí, otras veces definidas por el conflicto.

En este sentido podemos comprobar la hipótesis planteada en esta investigación al responder la pregunta de la misma ¿Cómo se construyen las identidades de los jóvenes dentro de las culturas juveniles en un establecimiento secundario de Cuenca? Para finalmente respondernos y verificarla afirmando: Las identidades juveniles se construyen a partir de la relación que se establecen los jóvenes con los colectivos, sus referentes y entornos, y el uso de los espacios públicos. Además, consideramos que es en la hora de recreo dentro del espacio institucionalizado que los jóvenes inician la formación de estas culturas juveniles, van construyendo su identidad y cuando se organizan van luego a ocupar el espacio público de la ciudad.

El territorio juvenil es un escenario de representaciones e imaginarios comunes, que los dota de cierta homogeneidad identitaria. ¿Hasta qué punto esta territorialidad construida por los jóvenes, revela usos y sentidos del espacio diferenciados por género? A través de un conjunto de señales, hombres y mujeres comparten la ropa, los mismos gustos, los miedos, deseos y subjetividades, y marcan sus límites y fronteras hacia fuera de su propio colectivo.

El espacio público es simbólicamente masculino. Los varones son quienes desde una posición de poder ejercen su autonomía y libertad para nombrar sus espacios y sus límites de movimiento; son ellos quienes transitan con seguridad las calles y las aceras, frente a las mujeres que recorren estos espacios con la imagen del temor y el riesgo, que se disipan en el momento en el que logran compañía.

Las entrevistas a profundidad que hemos realizado muestran que mientras los jóvenes varones se desplazan con mayor libertad en la noche y hacia la cancha, al parque, a la calle u otros lugares catalogados como de riesgo, las mujeres transitan los mismos lugares desde una situación de mayor vulnerabilidad y fragilidad. Son las amigas, los familiares o la presencia de un varón los que posibilitan el acceso a estos espacios.

Otra importante reflexión es la de ver el nombre que se les da a los grupos de jóvenes, catalogados como tribus o culturas juveniles, o quizá como subculturas. Fue el francés Michel Maffesoli quien acuñó el concepto de tribus urbanas, por primera vez. En las sociedades individualistas, las personas se agrupan en torno a gustos comunes y nuevas modalidades de solidaridad.

Estas condiciones, según Charles Feixa, no se ajustan totalmente al sector juvenil. Feixa ha realizado una distinción que consideramos útil en este punto. Las tribus contarían con relativa estabilidad, cierta consistencia en el tiempo, pertenencia a un universo simbólico y en un estilo de vida propio. Esta no condice con la observada en los grupos en estudio. Ellos, a diferencia de roqueros, punks, emos, entre otros, no rompen con el estilo de vida de sus progenitores ni introducen una diferencia con su cotidianidad. No poseen reglas específicas ni ritos de iniciación. Tampoco conforman una contracultura. Para Feixa, constituye más bien una cultura juvenil, dinámica, con fronteras porosas y borrosas. Según mi criterio, el fenómeno requiere de un mayor debate dentro del ámbito de las ciencias sociales. (Feixa, 1999)

En cuanto a la etnografía como punto de partida, exploración y desarrollo de esta investigación, se ha logrado dar cabida a la subjetividad de la observación participante. En tanto herramienta la considero vital y de suma importancia como manera de sensibilizar y experimentar una nueva forma de hacer investigación. Personalmente me ha servido mucho para adentrarme en el mundo interior de los jóvenes, por lo que puedo asegurar que la etnografía es una técnica ideal para la observación y la comprensión de estos grupos culturales. La etnografía es una técnica muy útil, tanto en lo vivencial como en lo formativo. Fue importante en el trabajo de campo porque se dieron algunos procesos emotivos entre el investigador y los sujetos de estudio, pues el contacto directo produce emotividad más sentida y, por lo tanto, más cercana a la vida misma de los jóvenes.

Mi experiencia en cuanto a la etnografía me involucró de tal manera que pude experimentar un contacto primero con mi subjetividad, luego la de los chicos, para así abarcar más y mejor mi experiencia personal con la experiencia humana y enriquecedora de los jóvenes que estaba explorando y conociendo. El observar un grupo juvenil trajo muchas ventajas, como también muchas lecciones de vida en materia de aprender a mirar y verse mirando. Después de este contacto con los jóvenes soy mucho más sensible con mi vida misma, en mi profesión y en mi trabajo.

La etnografía, como técnica ligada a la sociología cualitativa, entiende su labor en la comprensión e interpretación del punto de vista y el significado que asignan los agentes al mundo social que construyen interactivamente. Tiene un desarrollo que procede de la antropología y se utiliza para describir las situaciones y fenómenos que tienen lugar en las comunidades sociales, tales como son percibidas por sus miembros. Es una técnica que requiere necesariamente la presencia, durante un tiempo considerable, del investigador como observador de campo, sea participando de forma activa en la vida cotidiana, en este caso de las culturas juveniles, o como mero observador no participante. Pude ganarme la aceptación de los jóvenes y registrar sistemáticamente las observaciones en cuaderno de notas, grabadoras de audio, fotografía para comprender, interpretar y explicar los procesos que tienen lugar en el interior de estas culturas juveniles. 


\section{Referencias Bibliográficas}

Arce, T. (2008). Subcultura, contracultura, tribus urbanas y culturas ¿homogenización o diferenciación? REVISTA ARGENTINA DE SOCIOLOGÍA, 257-271.

Brito Lemus, R. (1998). Hacia una sociología de la juventud. Algunos elementos para la deconstrucción de un nuevo paradigma de la juventud. Última Década.

Cerbino, M. (1999). De malestares en la cultura, adicciones y jóvenes. ICONOS.

Contreras, T. (2005). Una aproximación a la producción intelectual en torno a la temática de los estudiantes secundarios contemporáneos. Un balance bibliográfico. Chile: Centro de Estudios en Seguridad Ciudadana (CESC).

Feixa, C. (1999). El reloj de arena, culturas Juveniles en México. Nueva Antropología.

Garcéz, M. Á. (2004). Nos-Otros los jóvenes. Pistas para su reconocimiento. Comunicación.

García Canclini, N. (2004). Diferentes, Desiguales y Desconectados. Mapas de la Interculturalidad. Barcelona: Gedisa.

Guber, R. (2001). La Etnografía, método, campo y reflexividad. Bogotá: Norma.

Guber, R. (2004). El Salvaje Metropolitano, Reconstrucción del conocimiento social en el trabajo de campo.
Buenos Aires: Paidós.

Habermas, J. (1981). Historia y crítica de la opinión pública. Barcelona: Gustavo Gili S.A.

Reguillo, R. (2000). Emergencias de Culturas Juveniles. Estrategias del desencanto. México: Norma.

Reguillo, R. (2003). Las culturas juveniles: un campo de estudio; breve agenda para la discusión. Revista Brasileira de Educación.

Stanton, G. (1996). La Metodología Etnográfica. , 60.

Recibido: 30 de junio de 2018

Aceptado: 3 de septiembre de 2018 
